\title{
Intestinal Maturation: In Vivo Magnesium Transport
}

\author{
RAYMOND MENEELY, LAURA LEEPER, AND.FAYEZ K. GHISHAN ${ }^{(19)}$ \\ Division of Gastroenterology-Nutrition, Vanderbilt University Medical Center, Department of Pediatrics, \\ Nashville, Tennessee, USA
}

\begin{abstract}
Summary
We investigated with an in vivo single pass perfusion technique net transport of magnesium in the jejunum, ileum and colon segments of suckling, weanling and adolescent rats. The concentration of magnesium in the isotonic sodium chloride solution perfused through the intestinal segments was either below $(0$ and 0.5 mmoles/liter) or above (1, 2.5 and 5 mmoles/liter) serum ionized magnesium. The relationship between net transport rates ( $\mu$ moles/h per $g$ dry weight) and luminal magnesium concentration was linear in all three intestinal segments of the suckling rats. In the weanling and adolescent rats, the relationship between net transport and luminal magnesium concentration was linear in the small intestinal segments; however, a change to a saturable, curvilinear relationship was noted in the colon segments. Rates of transport were significantly greater in all segments of suckling rats compared to corresponding segments of the adolescent rats, when luminal magnesium concentration was 2.5 and 5 mmoles/ liter. Net transport rates in the colonic segments at all ages were either equal to or greater than rates in the small intestinal segment at the same age period. The change in the relationship between transport rates and luminal magnesium in the colonic segments suggested that the mode of magnesium transport change at the time of weaning from mainly a passive mechanism in the suckling period to mainly a carrier mediated mechanism in the adolescent rats. This is the first demonstration of developmental characteristics of magnesium transport in animals.
\end{abstract}

\section{Speculation}

The change in the rate and characteristics of net magnesium transport in the rat during maturation reflects a greater permeability of the intestinal membranes'in the suckling compared to adolescent rats. The mechanism(s) responsible for the changes in the intestinal permeability could be the result of hormonal changes which occur during the weanling period.

In vivo and in vitro studies of intestinal magnesium transport revealed conflicting data regarding the site of maximal absorption $(2,6,12)$. Although in vivo perfusion studies showed greater absorption in proximal rather than distal small intestinal segments (12), the reverse was found by in vivo isotopic studies (5). An in vitro study showed the proximal intestine to be the maximal site of absorption (2); however, another study found the ileum to be the maximal site of absorption (13). Furthermore, the mechanism(s) involved in transport of magnesium across the epithelium of the small and large intestine are not completely understood. Behar (3), using in vivo rat perfusion, concluded that magnesium absorption occurs solely as a result of water flow by the "solvent drag" effect. However, Brannan et al. (4) in human perfusion studies showed that magnesium absorption was a saturable process in the small intestine when water flow was abolished. Ross (13), using in vitro everted gut sacs in the rat, has shown that magnesium transport was a saturable energy dependent process.
The previous studies examined the process of magnesium transport in adult humans or animals. To our knowledge there are no available studies on this process during the preweaning or weaning periods.

Our previous studies (7) on intestinal calcium absorption in the rat during maturation demonstrated a passive transport process in the suckling period, which changed to a saturable process during the weanling period. Inasmuch as a common transport system for absorption of magnesium and calcium was suggested $(1,5,14)$, we designed the current study to define the characteristics of magnesium transport in the small and large intestine of rats during maturation. Transport of magnesium was compared in vivo from luminal solutions containing magnesium at concentrations below and above expected ionized serum magnesium. The age group studied were the suckling (14-15 day old), weanling (21-22 day old), and adolescent (42 day old).

\section{MATERIALS AND METHODS}

After birth rat pups were distributed among mothers to maintain litter size at seven to nine pups until the time of study. Animals were raised under usual laboratory conditions. Intestinal absorption was determined in suckling (14-15 days), weanling (21-22 days), and adolescent (42-45 day) rats. Content of magnesium in the breast milk ingested by the suckling and weanling rats was approximately $185 \mathrm{mg} /$ liter. Content of magnesium in the regular rat chow was $0.2 \%$. At the time of study unfasted rats were anesthetized with an intraperitoneal injection of an ethylureaphenobarbital mixture (6:1) (K \& K Laboratories, Plainview, NY) at a dose of $0.2 \mathrm{ml} / 100 \mathrm{~g}$ body weight. After opening the abdominal cavity, 10-15 segments of jejunum, ileum and the entire colon excluding the cecum were isolated, cannulated, flushed with 20 $\mathrm{ml}$ of warm normal saline and then with $20-30 \mathrm{ml}$ of air. The cannulated segments were then returned to the abdominal cavity. Body temperature of the rats was maintained at $36-37^{\circ} \mathrm{C}$ during the entire perfusion. The cannulated segments were perfused in situ at a rate of $0.4 \mathrm{ml} / \mathrm{min}$. The perfusion solution contained per liter: 154 mmoles sodium chloride, $30 \mathrm{mg}$ phenol red (as a nonabsorbable marker for volume changes) and $\mathrm{MgCL}_{2}$ in concentration either below $(0,0.5 \mathrm{mM})$ or above $(1,2.5,5 \mathrm{mM})$ serum ionized magnesium. After the start of the perfusion, a 30-min period was allowed to attain a steady state condition. Perfusates were then collected during the next three consecutive 20 -min periods. At the end of the perfusion periods, weight was determined after expressing the contents gently with forefingers. The segments were then dried in a vacuum oven at $95^{\circ} \mathrm{C}$ for $24 \mathrm{~h}$ and the dry weight was determined. Phenol red in the perfusion solutions and perfusates was determined by a spectrophotometer with a previously described method (15). Previous recovery studies of phenol red during perfusion in all segments of three age groups showed $\sim 97-98 \%$ recovery of total phenol red perfused $(11,17)$. Magnesium concentration in the solutions was determined by an atomicabsorption spectrophotometer.

Disappearance of magnesium from the lumen was taken to 
indicate net absorption, (positive values) and addition of magnesium was taken to indicate secretion (negative values). The calculation is shown below:

Net $\mathrm{Mg}$ absorption, $\mu$ moles $/ 20 \mathrm{~min}$

$$
=\mathrm{Vi}([\mathrm{Mg}] \mathrm{i}-[\mathrm{Mg}] \mathrm{f}[\mathrm{PRi} / \mathrm{PRf}])
$$

where $\mathrm{V}$ is volume perfused in each segment in $\mathrm{ml} / 20$ mins; $[\mathrm{Mg}]$ is total concentration of $\mathrm{Mg}$ as $\mu \mathrm{moles} / \mathrm{ml}$; $\mathrm{PR}$ is phenol red concentration in $\mu \mathrm{g} / \mathrm{ml}$. Subscript $\mathrm{i}$ and $\mathrm{f}$ refers to initial values (i) in the perfusion fluid before perfusion and in the perfusate collected (f), respectively. Absorption rates at 20 -min periods did not vary more than $20 \%$ within each rat indicating a steady state. They were added to obtain amount aborbed per $h$. In order to compare transport rates of magnesium in segments from rats of different age groups, the quantities transported were normalized for the marked difference in the weights of the perfused segments. Transport rates were expressed per unit dry weight to indicate "absorptive specific activity" of segment.

Statistical analysis. The unpaired Student's $t$ test was used for statistical comparison of differences between mean values obtained for the rats at the different ages. A $P$ value $(10)$ of less than 0.05 was considered to indicate a statistically significant difference between two mean values. For Figure 1, the method of least square curves fit was used to determine the best linear function. For the colonic segments in the weanling and adolescent periods a Lineweaver double reciprocal plot was used to calculate $\mathrm{Km}$ and Imax values.

\section{RESULTS}

Mean body weight and measurements of the perfused jejunum, ileum and colon in suckling (14-15 day), weanling (21-22 day), and adolescent rats (42-45 day) are shown in Table 1 . At each age period, 5-6 rats had all segments perfused with a solution containing $\mathrm{MgCl}_{2}$ in concentration from $0 \mathrm{mM}, 0.5 \mathrm{mM}, 1.0 \mathrm{mM}, 2.5$ $\mathrm{mM}$ and $5.0 \mathrm{mM}$. Table 2 displays mean net absorption, expressed as $\mu$ moles per $\mathrm{h}$ per $\mathrm{g}$ of dry weight of intestinal segments, for each age group at each $\mathrm{MgCl}_{2}$ concentration.

Figure 1 depicts the relationship between net magnesium transport and luminal magnesium concentration of all the intestinal segments of the rats studied.

Findings in the jejunal segments. The relationship between net transport rates and luminal magnesium concentration was linear in the three age periods studied. The data of each period fits a straight line when analysed using the formula $\mathrm{Y}=\mathrm{A}+(\mathrm{B} \times \mathrm{X})$ of the least square fit. There was net secretion of magnesium into the lumen when luminal magnesium concentration was zero. Net secretion rates were similar in the suckling and adolescent rats. At 2.5 and $5 \mathrm{mM}$ of luminal magnesium concentration, transport rates were significantly greater in segments of the suckling compared to corresponding segments of adolescent rats $(P<0.05)$. Transport rates for the weanling period were intermediate between values of the suckling and adolescent periods.

Findings in the ileal segments. The relationship between net transport rates and luminal magnesium concentration was linear
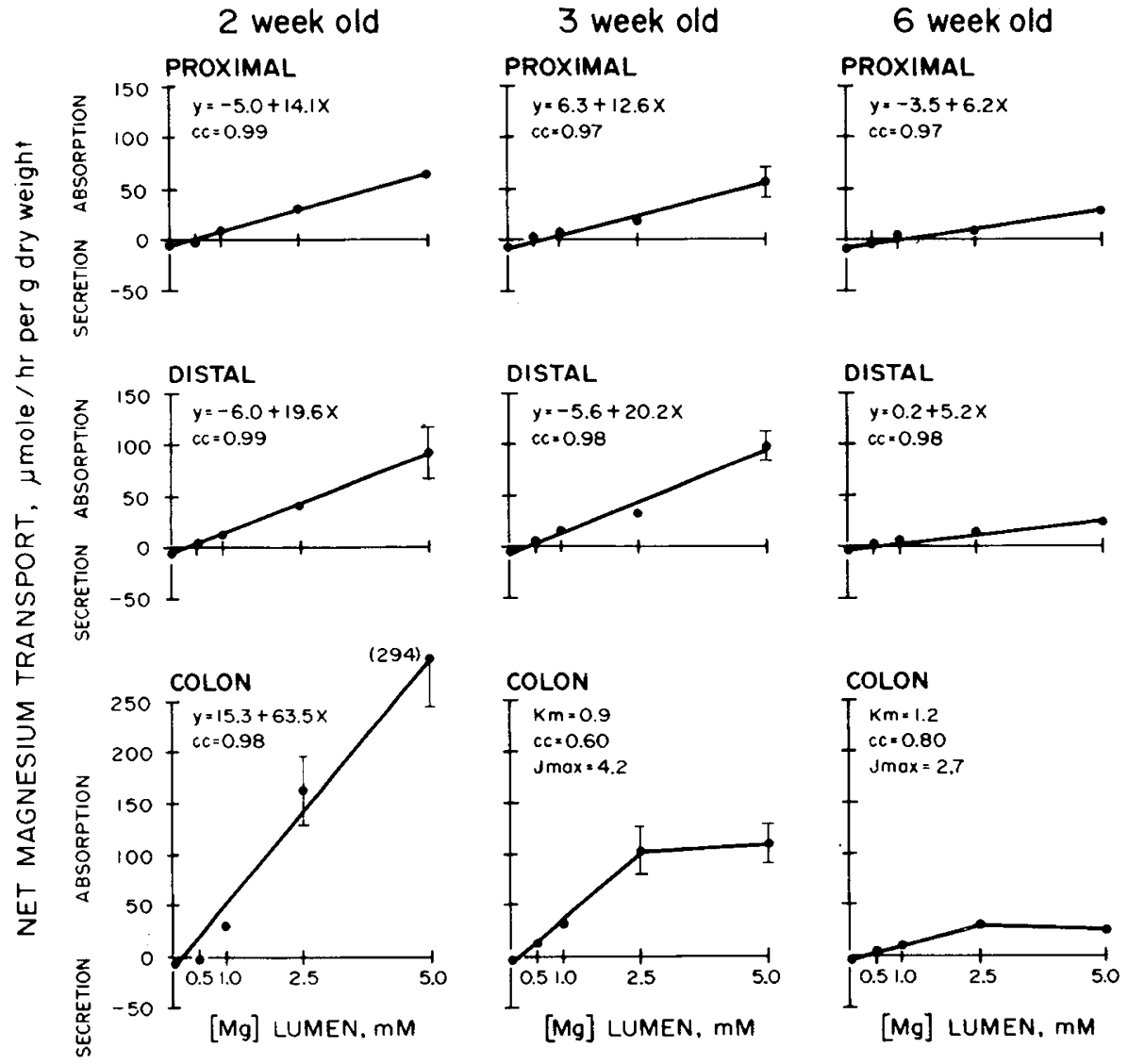

Fig. 1. The relationship between rate of absorption of magnesium and the initial concentration of magnesium in the solution perfusing segments of the proximal and distal small intestine and the colon. Net absorption represents the rate of disappearance of magnesium from the lumen during perfusion. The symbols depict mean values and the bars the S.E. In most cases, the S.E. was small and could not be shown on the graph. In the proximal and distal small intestinal segments of all age periods, the relationship between net transport rate and luminal magnesium concentration was linear as evident by a straight line fit using the formula $Y=A+(B \times X)$ of the least square fit curves. In the colon segments of the suckling rats the relationship between net transport rate of magnesium and luminal magnesium concentration was also linear; however, a curvilinear relationship was noted in the weanling and adolescent rats. The transport data for the colon fits Michaelis-Menten kinetics with $\mathrm{Km}$ of 0.9 and $1.2 \mathrm{mmoles} / \mathrm{liter}$ for the weanling and adolescent rats colon respectively. There were statistical differences between the slopes of the suckling and adolescent rats at all segments $(P<0.001)$. This indicates that the permeability coefficient was greater in the suckling compared to the adolescent rats. 
Table 1. Body weight and measurements of the intestinal segments in the groups of rats studied

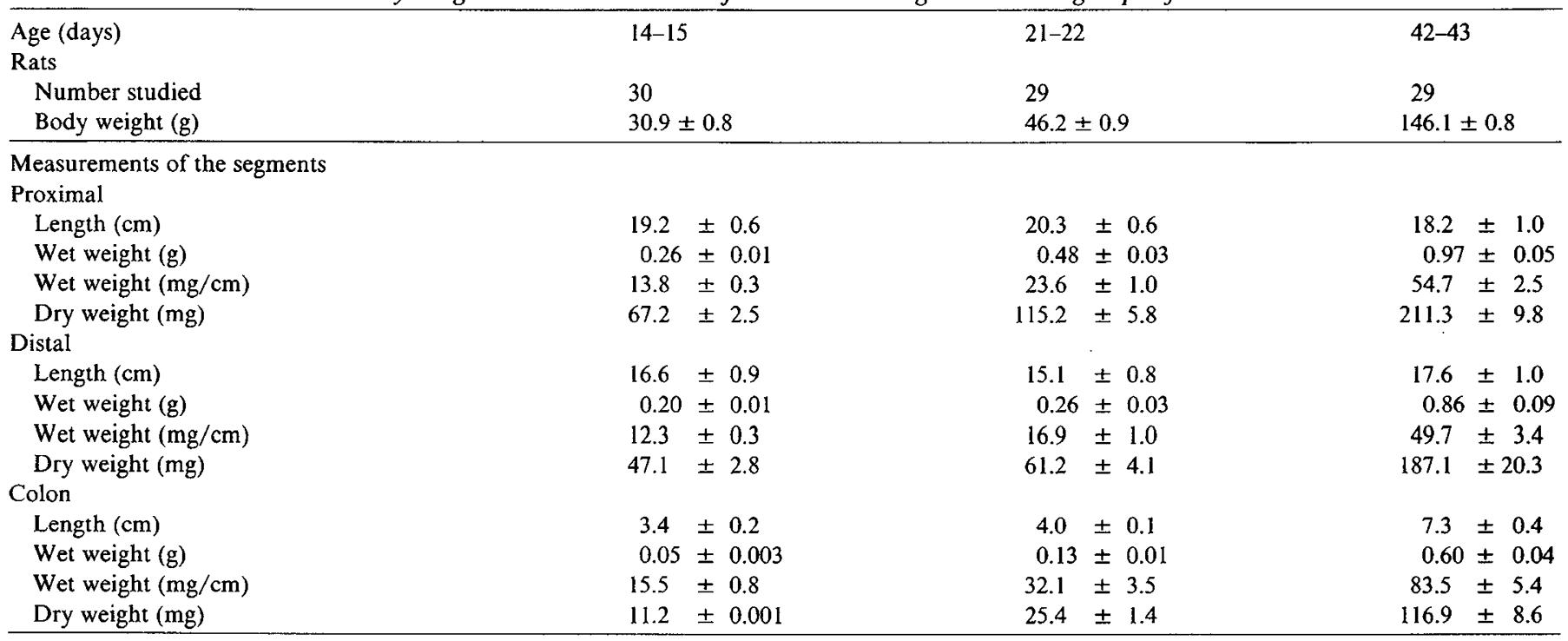

${ }^{1}$ Values are mean \pm S.E.

Table 2. Net absorption of magnesium in the perfused segments of the rats studied expressed as $\mu M / h / g$ dry weight of the segments ${ }^{1}$

\begin{tabular}{|c|c|c|c|c|c|}
\hline $\begin{array}{c}\text { Magnesium } \\
\text { concentration }\end{array}$ & 0 & 0.5 & 1.0 & 2.5 & 5.0 \\
\hline \multicolumn{6}{|l|}{$(\mathrm{mM})$} \\
\hline \multicolumn{6}{|l|}{ Age } \\
\hline jejunum & $-2.6 \pm 0.8$ & $-0.3 \pm 0.1$ & $7.7 \pm 1.6$ & $32.0 \pm 0.3^{2}$ & $66 \pm 9^{2}$ \\
\hline ileum & $-1.8 \pm 0.8$ & $1.4 \pm 1$ & $11 \pm 2.0$ & $43 \pm 6.4^{2}$ & $93 \pm 24^{2}$ \\
\hline colon & $-1.2 \pm 0.2$ & $-0.2 \pm 1$ & $33 \pm 6.3^{2}$ & $169 \pm 33^{2}$ & $295 \pm 49^{2}$ \\
\hline ileum & $-1.8 \pm 0.2$ & $5.1 \pm 0.8$ & $16 \pm 2.8$ & $34 \pm 9.0$ & $101 \pm 12$ \\
\hline colon & $-1.7 \pm 0.1$ & $11.6 \pm 3.3$ & $31 \pm 6.0$ & $102 \pm 22$ & $109 \pm 18$ \\
\hline \multicolumn{6}{|l|}{$6 \mathrm{wk}$} \\
\hline jejunum & $-3.5 \pm 0.5$ & $-0.1 \pm 0.5$ & $4.7 \pm 0.8$ & $8.2 \pm 2.2$ & $29 \pm 6.5$ \\
\hline ileum & $-0.9 \pm 0.2$ & $1.7 \pm 0.9$ & $6.4 \pm 2.0$ & $15 \pm 3.0$ & $25 \pm 3.0$ \\
\hline colon & $-1.2 \pm 3.6$ & $1.9 \pm 1.2$ & $10.6 \pm 1.6$ & $31 \pm 8.0$ & $27 \pm 5.0$ \\
\hline
\end{tabular}

${ }^{1}$ Values are mean \pm S.E.

${ }^{2}$ Mean values at suckling periods are significantly greater than corresponding mean values at adolescent age periods.

in the three age group periods studied. The data of each period fits a straight line when analysed using the formula $Y=A+(B$ $X X)$ of the least square fit. Findings in the ileal segments were similar to those in the jejunal segments at all age groups studied.

Findings in the colonic segments. The relationship between net transport rates and luminal magnesium concentration was linear in the suckling period; however, a change to a saturable process was noted in the weanling and adolescent rats. A Lineweaver double reciprocal plot of the transport data indicates that the curve fits a Michaelis-Menten kinetics with $\mathrm{Km}$ of $0.9 \mathrm{mM}$ in colon of weanling rats and $1.2 \mathrm{mM}$ in colon of adolescent rats. These values are based on one point outside the linearity and essentially there was no difference between $\mathrm{Km}$ value for both weanling and adolescent rats.

Net secretion rate of magnesium into the lumen in all three age groups were similar when the luminal concentrations of magnesium was zero. However, at luminal magnesium concentrations of $1 \mathrm{mM}, 2.5 \mathrm{mM}$ and $5 \mathrm{mM}$, there was significantly greater net absorption of magnesium in the segments of suckling compared to corresponding segments of the adolescent rats $(P<0.05)$. Transport rates for the segments of the weanling rats were intermediate between values of suckling and adolescent rats.

\section{DISCUSSION}

Although intestinal magnesium transport has been studied by numerous investigators, there has been little concurrence on the site of maximal absorption or the mechanism(s) responsible for the transport of this essential mineral.

In man, based on the time curve of the appearance in blood or orally administered isotopes, the proximal small intestine was considered the major site of magnesium absorption (9). Using intestinal perfusion of $\mathrm{MgCl}_{2}$ in man, Brannan et al. (4) found similar rates of transport in the jejunal and ileal segments.

In rats, ${ }^{28} \mathrm{Mg}$ uptake by everted gut sacs was shown to be maximal in the proximal small intestine with progressive decrease distally (2). Chutkow (6) using in vivo isotopic studies in rats demonstrated that magnesium is absorbed throughout the intestinal tract with over $70 \%$ of total absorption occurring in the colon. In vivo perfusion studies in rats showed greater absorption in the duodenum than in the ileum (12). However, another in vivo perfusion study found similar transport rates in the ileum and colon segments (3).

All of the previous investigations have been carried out in adult 
animals and the process of intestinal transport of magnesium during maturation is not known.

In the current study, magnesium was transported out of the lumen in all segments including jejunum, ileum and colon at all three age periods. At all age periods, transport rates of magnesium were not significantly different in the jejunal and ileal segments. In the suckling period, net magnesium transport in the colon was significantly greater than corresponding mean values in the jejunal and ileal segments. Statistical analysis of the differences in the slopes of the adolescent and suckling rats at all three segments was significant $P<0.001$. Since the slopes are a reflection of the permeability coefficient, this would indicate that the intestinal membranes are more permeable at the suckling period than in the adolescent period.

Studies on the mechanism(s) of magnesium transport have been conflicting (2, 13). Aldor and Moore (2) showed in an in vitro everted gut sacs preparation that magnesium was transported by a simple ionic diffusion process across the intestinal epithelium of rats. However, Ross (13) demonstrated that magnesium was transported by an active energy requiring process in the rat using everted gut sacs.

In vivo perfusion studies in the rat showed that magnesium was transported mainly by bulk water movements (3). However, perfusion studied in man demonstrated a saturable process for magnesium transport when net water movement was near zero (4).

The current study demonstrates that magnesium absorption is a linear function of luminal magnesium concentration between 0 and $5 \mathrm{mM}$ in jejunum and ileum segments of the suckling, weanling and adolescent rats. This suggests that magnesium transport across the small intestinal segments is mainly by a passive process.

In the colonic segments of the suckling rats, a similar linear relationship was also noted. This observation suggests that magnesium transport occurs along the entire intestinal tract in the suckling rats by a passive process. This finding was similar to our previous study on calcium transport in the suckling rats (7).

During the time of weaning, a change in the process of magnesium transport to a saturable one occurs in the colonic segments of the weanling and adolescent rats. However, no such change in the process of transport was noted in segments of the small intestine.

The factors responsible for this transition in magnesium transport are not known, but some of the events that occur at the time of weaning should be considered. Our previous studies on calcium transport have indicated that the bidirectional fluxes of calcium was several-fold greater in the suckling rats compared to adolescent rats. These findings, along with our current studies, which demonstrate that the permeability coefficient was significantly greater in the suckling period than in the adolescent period, suggest a greater permeability of the intestinal membranes in the suckling compared to adolescent rats $(7,8,18)$. Around the time of weaning, the permeability of the intestinal membrane decreases $(7,8,18)$. Furthermore, the colonic segments are known to possess smaller pore size of the paracellular pathways than the small intestinal pores (16). These results imply a change in the mechanism of intestinal magnesium transport during maturation. This change occurred during the time of weaning, a critical period of development in the rat.

\section{REFERENCES AND NOTES}

1. Alcock, N. and Maclntyre, I.: Interrelation of calcium and magnesium absorption. Clin. Sci., 22: 185 (1962).

2. Aldor, T. A. M. and Moore, E. W.: Magnesium absorption by everted sacs of rat intestine and colon. Gastroenterology, 59: 745 (1970).

3. Behar, J.: Magnesium absorption by the rat ileum and colon. Am. J. Physiol., 227: 334 (1974).

4. Brannan, P. G., Vergne-Marini, P, Pak, C., Hull, A., and Fordtran, J.: Magnesium absorption in the human small intestine. J. Clin. Invest., 57: 1412 (1976).

5. Care, A. D. and Van't Klooster, A. T.: In vivo transport of magnesium and other cations across the wall of the gastrointestinal tract of sheep. J. Physiol., 177: 174 (1965).

6. Chutkow, J. G.: Site of magnesium absorption and excretion in the intestinal tract of the rat. J. Lab. Clin. Med. 63: 71 (1964).

7. Ghishan, F. K., Jenkins, J. T., and Younoszai, M. K.: Maturation of calcium transport in the rat small and large intestine. J. Nutr., 110: 1622 (1980).

8. Ghishan, F. K., Jenkins, J. T., and Younoszai, M. K.: Intestinal calcium loss in infant rats. Proc. Soc. Exp. Biol. and Med., 161: 70 (1979).

9. Graham, L. A., Caesar, J. J., and Burger, A. S. V.: Gastrointestinal absorption and excretion of ${ }^{28} \mathrm{Mg}$ in man. Metab. Clin. Exp., 9: 646 (1960).

10. Huntsberger, D. V. and Leaverton, P. E.: Statistical inference in the biomedical sciences. In: D. V. Huntsberger and P. E. Leaverton, Eds., (Allyn and Bacon, Inc., Boston, MA, 1970).

11. Miller, D. L. and Schedi, H. P.: Total recovery studies of nonabsorbable indicators in the rat small intestine. Gastroenterology, 58: 40 (1970).

12. Petith, M. M. and Schedl, H. P.: Effect of magnesium deficiency on duodenal and ileal magnesium absorption and secretion. Dig. Dis., 23: 1 (1978).

13. Ross, D. B.: In vitro studies on the transport of magnesium across the intestinal wall of the rat. J. Physiol., 160: 417 (1963).

14. Schachter, D. and Rosen, S. M.: Active transport of $\mathrm{Ca}^{45}$ by the small intestine and its dependence on vitamin D. Am. J. Physiol., 196: 357 (1959).

15. Schedl, H. P. and Clifton, J. A.: Small intestinal absorption of steroids. Gastroenterology, 41: 491 (1965).

16. Turnberg, L. A.: Intestinal transport of salt and water. Clin. Sci., 54: 337 (1978).

17. Younoszai, M. K., Saprio, R. S., and Laughlin, M.: Maturation of jejunum and ileum in rats: water and elecltrolyte transport during in vivo perfusion of hypertonic solutions. J. Clin. Invest., 62: 271 (1978).

18. Younoszai, M. K. and Ghishan, F. K.: In vivo intestinal calcium transport: normal and growth retarded. J. Nutr. 109: 573 (1979)

19. Requests for reprints should be addressed to: Dr. Fayez K. Ghishan, Assistant Professor, Dept. of Pediatric Gastroenterology, Vanderbilt University Medical Center, Nashville, TN 37040.

20. This research was supported by Biomedical Research Grant Number RR0542418.

21. Received for publication February 20, 1981

22. Accepted for publication August 20, 1981. 